\title{
Application of an Antimicrobial Protein Film in Beef Patties Packaging
}

\author{
Ji-Hyun Lee and Kyung Bin Song* \\ Department of Food Science and Technology, Chungnam National University, Daejeon 34134, Korea
}

\begin{abstract}
This study was performed to apply a protein film containing a natural antimicrobial compound to meat packaging and determine quality change of meat during storage. Proteins obtained from the by-products of food processing have been utilized as biodegradable film sources. Porcine meat and bone meal (MBM) is obtained during meat processing, and proteins from the MBM can be extracted and used as a film base material. Previously, an antimicrobial MBM film containing coriander oil (CO) was prepared and its physical properties and antimicrobial activity were characterized. In this study, the antimicrobial MBM-CO film was applied to beef patties packaging, and the microbial population and the degree of lipid oxidation were determined during storage at $4^{\circ} \mathrm{C}$ for $15 \mathrm{~d}$. The population of inoculated E. coli $\mathrm{O} 157: \mathrm{H} 7$ in the samples wrapped with the MBM-CO film was $6.78 \mathrm{log}$ colony forming unit (CFU)/g after $15 \mathrm{~d}$ of storage, whereas the control had $8.05 \mathrm{Log} \mathrm{CFU} / \mathrm{g}$, thus reducing the microbial population by $1.29 \mathrm{Log} \mathrm{CFU} / \mathrm{g}$. In addition, retardation of lipid oxidation in the patties was observed during storage for the samples packaged by the MBM-CO film, compared with the control samples. These results suggest that the MBM-CO film can be useful for enhancing the quality of beef patties during storage.
\end{abstract}

Keywords: antimicrobial compound, beef patty, packaging, protein film

Received July 6, 2015; Revised August 4, 2015; Accepted August 11, 2015

\section{Introduction}

Microbial growth in foods affects food safety and quality in general, and lipid oxidation particularly deteriorates the quality of beef products by changing the color and flavor of the foods during storage (Ladikos and Lougovois, 1990). Therefore, anti-oxidative and antimicrobial food packaging can be considered in the food industry.

As an alternative to plastic packaging materials with environmental concerns, biodegradable packaging materials have been studied (Khwaldia et al., 2010). Proteins from the by-products of the food industry have been used as biodegradable packaging materials (Song et al., 2013). In particular, protein films can carry antioxidants and antimicrobials, and as an example essential oils are applied to the films. To utilize a by-product of meat processing, a porcine meat and bone meal (MBM) film containing coriander oil $(\mathrm{CO})$ was prepared and characterized in the previous study (Lee et al., 2015a). Based on the previous results, in this study, to utilize the biodegradable film for food packaging, the antimicrobial MBM-CO film was

\footnotetext{
*Corresponding author: Kyung Bin Song, Department of Food Science and Technology, Chungnam National University, Daejeon 34134, Korea. Tel: +82-42-821-6723, Fax: +82-42-8252664, E-mail: kbsong@cnu.ac.kr
}

used for beef patties packaging and its antimicrobial and anti-oxidative property was evaluated to extend the shelf life of the beef patties.

\section{Materials and Methods}

\section{Materials}

MBM was obtained from a local market (Korea). CO was obtained from The Certification Academy for Holistic Aromatherapy (Korea). Minced beef was purchased from a local market (Korea). After minced beef was battered without any additive, beef patties (diameter, $8.5 \mathrm{~cm}$; thickness $1.2 \mathrm{~cm}$ ) were prepared using a petri dish in the laboratory.

\section{Application of the MBM-CO film to beef patties packaging}

MBM and MBM-CO films were prepared according to the method described by Lee et al. (2015b). For the preparation of MBM-CO film, $5 \mathrm{~g}$ of MBM protein, $2 \mathrm{~g}$ of fructose, $1 \mathrm{~g}$ of $\mathrm{CO}$, and $0.02 \mathrm{~g}$ of tannic acid were dissolved in the film-forming solution $(100 \mathrm{~mL})$. The filmforming solution was then poured onto a Teflon-coated plate and dried at room temperature for $24 \mathrm{~h}$. The dried films were peeled off and used for beef patties packaging. The film for packaging had the physical properties of

(9)This is an open access article distributed under the terms of the Creative Commons Attribution Non-Commercial License (http://creativecommons.org/licences/ by-nc/3.0) which permits unrestricted non-commercial use, distribution, and reproduction in any medium, provided the original wokr is properly cited. 
13.23 MPa of tensile strength and $69.21 \%$ of elongation at break as well as optical properties of $23.64 \%$ opacity and $27.72 \%$ transparency (Lee et al., 2015b).

Beef patties were cut to the same weight $(10 \mathrm{~g})$, and the surface was sterilized using UV for $10 \mathrm{~min}$. A $0.5-\mathrm{mL}$ sample of E. coli $\mathrm{O} 157: \mathrm{H} 7\left(10^{6} \mathrm{CFU} / \mathrm{g}\right)$, which was cultured in TSB at $37^{\circ} \mathrm{C}$ for $24 \mathrm{~h}$, was spread onto each side of the patties. After drying for $30 \mathrm{~min}$, the patties were wrapped with the MBM film without CO or the MBMCO film so the films would be in direct contact with the samples. The control sample was kept in polyethylene terephthalate boxes only, and all samples were stored at $4^{\circ} \mathrm{C}$. Microbial enumeration and lipid oxidation determination were performed every three days during storage.

\section{Microbial analysis}

After adding $0.1 \%$ peptone water to beef patties $(10 \mathrm{~g})$, the mixture was homogenized using a stomacher (MIX 2, AES Laboratoire, France) for $3 \mathrm{~min}$. The inoculated samples were serially diluted, plated onto MacConkey agar (BBL), and incubated at $37^{\circ} \mathrm{C}$ for $24 \mathrm{~h}$. Microbial counts were expressed as the log of CFU. Experiments were analyzed in triplicate.

\section{Lipid oxidation}

To evaluate lipid oxidation, the thiobarbituric acid (TBA), peroxide value (POV), and metmyoglobin (MetMb) content were measured. TBA was assessed by the method described by Vyncke (1970) with minor modifications. Samples $(2 \mathrm{~g})$ were homogenized with $10 \mathrm{~mL}$ of $7.5 \%$ trichloroacetic acid using a stomacher for $8 \mathrm{~min}$, and 5 $\mathrm{mL}$ of TBA reagent $(0.02 \mathrm{M} 2$-thiobarbituric acid in distilled water) were added to $5 \mathrm{~mL}$ of the filtrate and boiled for $45 \mathrm{~min}$. After heating, the absorbance was measured at $539 \mathrm{~nm}$, and the TBA value was expressed as $\mathrm{mg}$ of malonaldehyde (MDA) per $\mathrm{kg}$ of sample (mg MDA/kg sample).

To evaluate POV, samples $(2 \mathrm{~g})$ were blended with 30 $\mathrm{mL}$ of acetic acid:chloroform $(3: 2, \mathrm{v} / \mathrm{v})$, and saturated potassium iodide was added. After storing for $5 \mathrm{~min}$ in the dark, $30 \mathrm{~mL}$ of distilled water was added, a $1 \%$ starch solution was added, and the solution was titrated with $0.01 \mathrm{~N}$ sodium thiosulfate. The POV was calculated and expressed as $\mathrm{mEq}$ peroxides $/ \mathrm{kg}$ sample.

MetMb content was determined according to the method of Fernández-López et al. (2003). Myoglobin was extracted from minced patties $(2 \mathrm{~g})$ using $20 \mathrm{~mL}$ of 0.04 $\mathrm{M}$ phosphate buffer ( $\mathrm{pH}$ 6.8), and the supernatant was filtered through Whatman paper (\#42) after centrifugation at $10,000 \mathrm{~g}$ for $30 \mathrm{~min}$. The absorbances at $525 \mathrm{~nm}, 572$ $\mathrm{nm}$, and $730 \mathrm{~nm}$ were measured, and MetMb content (\%) was calculated.

\section{Statistical analysis}

All experiments were performed triplicate $(n=3)$, and all data are represented as the means \pm the standard deviations (SD). SAS program version 8.0 (SAS, 2000) was used to perform analysis of variance and Duncan's multiple range tests $(p<0.05)$.

\section{Results and Discussion}

\section{Microbiological analysis of beef patties}

The changes in the populations of E. coli $\mathrm{O} 157: \mathrm{H} 7$ inoculated on beef patties were evaluated (Fig. 1). The initial population of E. coli $\mathrm{O} 157: \mathrm{H} 7$ in the sample was $5.13 \mathrm{Log}$ CFU/g. The microbial population increased during storage, and the populations of the control were significantly different from those of the patties wrapped with the MBM-CO film during storage. The population of $E$. coli $\mathrm{O} 157: \mathrm{H} 7$ in the samples packaged with the MBMCO film was 4.29 Log CFU/g after $3 \mathrm{~d}$ of storage, whereas the control had 5.65 Log CFU/g, thus reducing the microbial population by $1.36 \mathrm{Log} \mathrm{CFU} / \mathrm{g}$. The patties with the MBM film packaging also had fewer microbial populations than the control during the early stages of storage, most likely because the film absorbed water from the patties and delayed the microbial growth (Zivanovic et al., 2005). In addition, tannic acid, used as a cross-linking agent, might provide antimicrobial activity because of the presence of a galloyl group, which binds to iron from the

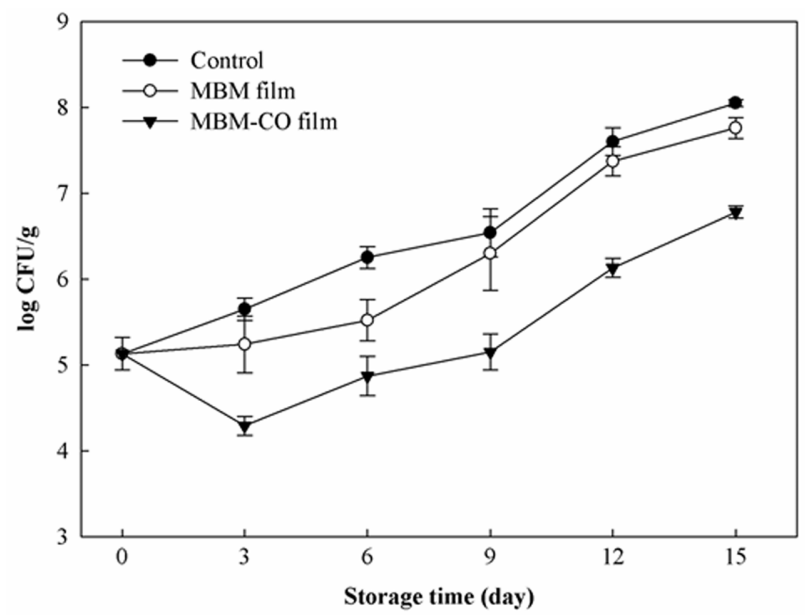

Fig. 1. Changes in the population of $E$. coli $0157: \mathrm{H} 7$ inoculated on beef patties during storage. 
Table 1. Changes in the POV of beef patties during storage (meq peroxide/kg sample)

\begin{tabular}{ccccccc}
\hline \hline \multirow{2}{*}{ Packaging method } & \multicolumn{5}{c}{ Storage time $(\mathrm{d})$} \\
\cline { 2 - 6 } & 0 & 3 & 6 & 9 & 12 & 15 \\
\hline Control & $0.37 \pm 0.17^{\mathrm{Da}}$ & $1.01 \pm 0.01^{\mathrm{Ca}}$ & $1.60 \pm 0.15^{\mathrm{Ba}}$ & $1.62 \pm 0.30^{\mathrm{Ba}}$ & $2.11 \pm 0.35^{\mathrm{ABa}}$ & $2.38 \pm 0.12^{\mathrm{Aa}}$ \\
MBM film & $0.37 \pm 0.17^{\mathrm{Ea}}$ & $0.54 \pm 0.21^{\mathrm{DEb}}$ & $1.13 \pm 0.48^{\mathrm{CDab}}$ & $1.45 \pm 0.14^{\mathrm{BCa}}$ & $1.91 \pm 0.39^{\mathrm{ABa}}$ & $2.18 \pm 0.32^{\mathrm{Aa}}$ \\
MBM-CO film & $0.37 \pm 0.17^{\mathrm{Ba}}$ & $0.38 \pm 0.13^{\mathrm{Bb}}$ & $0.63 \pm 0.11^{\mathrm{ABb}}$ & $0.73 \pm 0.34^{\mathrm{ABb}}$ & $0.87 \pm 0.32^{\mathrm{ABb}}$ & $1.16 \pm 0.32^{\mathrm{Ab}}$ \\
\hline
\end{tabular}

$\overline{\mathrm{a}, \mathrm{b}}$ Any means in the same column followed by different letters are significantly $(p<0.05)$ different by Duncan's multiple range test.

${ }^{\mathrm{A}-\mathrm{E}}$ Any means in the same row followed by different letters are significantly $(p<0.05)$ different by Duncan's multiple range test.

media and inhibits microbial growth (Kim et al., 2010). However, because only a small quantity of tannic acid was incorporated, its effects did not remain until the end of the storage time. After $15 \mathrm{~d}$ of storage, the population of E. coli $\mathrm{O} 157: \mathrm{H} 7$ in the samples packaged with the MBM-CO film was $6.78 \mathrm{Log} \mathrm{CFU} / \mathrm{g}$, whereas the control had $8.05 \mathrm{Log} \mathrm{CFU} / \mathrm{g}$.

\section{Lipid oxidation in beef patties during storage}

Lipid oxidation was evaluated by POV, TBARS, and MetMb content (Table 1, Fig. 2). The initial POV was $0.37 \mathrm{mEq}$ peroxide $/ \mathrm{kg}$ sample, and the POV of all samples increased during storage. The control had a higher POV than the samples packaged with the MBM-CO films, and the MBM film packaging also showed less $(p<0.05) \mathrm{POV}$ than the control until six days in storage. These results can be attributed to the oxygen barrier property of the MBM films that retards the diffusion of oxygen to the surface of the patties (Jeon et al., 2002). Nowzari et al. (2013) also reported that the POV of rainbow trout with chitosan film or chitosan-gelatin bilayer film coating were lower than those of the control samples during storage. In the present study, the POV of the samples packaged with the MBM-CO film was $1.16 \mathrm{mEq}$ peroxide/kg sample after $15 \mathrm{~d}$ of storage compared with $2.38 \mathrm{mEq}$ peroxide/ $\mathrm{kg}$ sample in the control, and the decrease was mainly

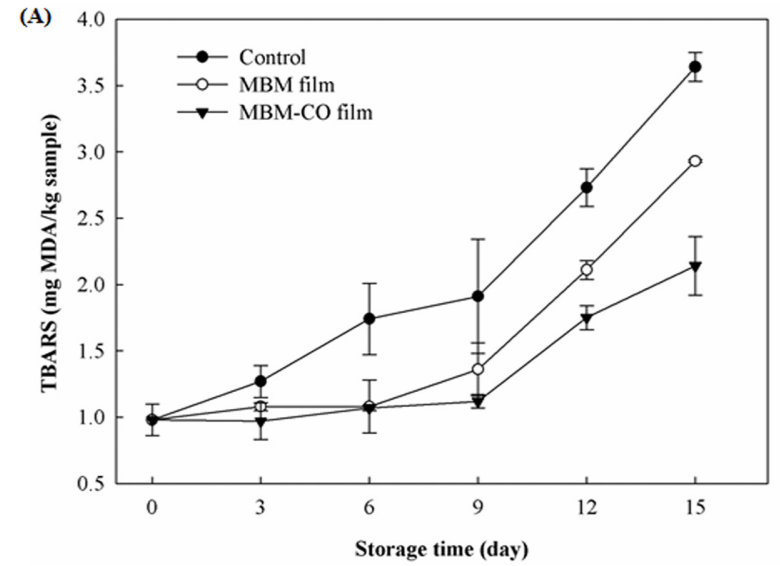

attributed to the effect of $\mathrm{CO}$ on the patties.

Fig. 2 shows the TBARS for the different packaging materials during storage. The TBARS of the control increased from 0.98 to $3.64 \mathrm{mg}$ malonaldehyde $/ \mathrm{kg}$ sample as storage time increased. In contrast, the MBM-CO packaged samples had the lowest TBARS values of $2.14 \mathrm{mg}$ malonaldehyde/kg sample, compared with the control and MBM packaged samples. Similar to our results, fish samples packaged with chitosan-cinnamon oil had lower TBARS compared with the control (Ojagh et al., 2010). Lee et al. (2015a) also reported that the cheese wrapped with chicken feet protein film containing clove bud oil had low TBARS value than the control.

$\mathrm{MetMb}$ content was also measured to evaluate the changes in lipid oxidation in the patties (Fig. 2). MetMb content increased during storage for all samples, and control samples had higher MetMb values than that of the MBM-CO samples during storage. The decrease of $\mathrm{MetMb}$ content might be due to the anti-oxidative properties of $\mathrm{CO}$ that delay radical generation in the patties (Qin et al., 2013).

\section{Conclusion}

The MBM film containing 1\% CO was applied to the packaging of beef patties. A reduction in the population

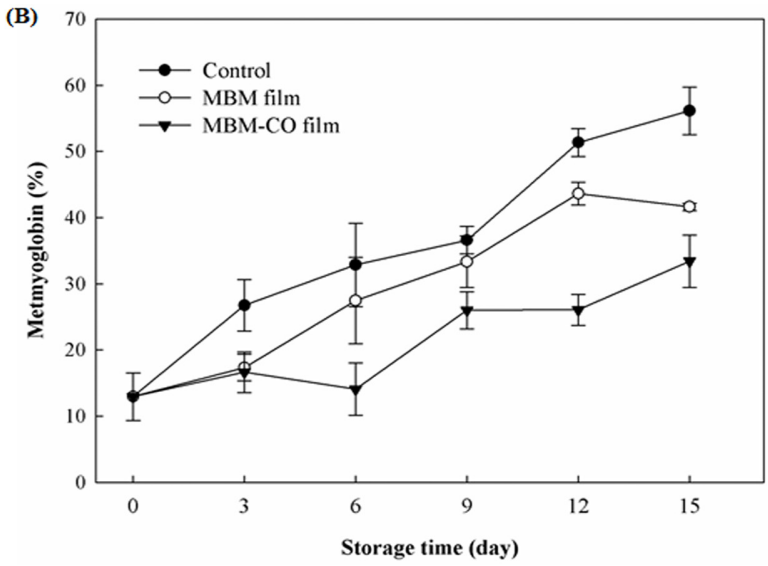

Fig. 2 Changes in TBARS value (A) and MetMb content (B) of beef patties during storage. 
of inoculated E. coli $\mathrm{O} 157: \mathrm{H} 7$ and retardation of lipid oxidation in the patties were observed during storage for the samples packaged by the MBM-CO film. Therefore, MBM film containing $\mathrm{CO}$ can be used as an effective packaging material to preserve the quality of beef patties during storage.

\section{Acknowledgment}

This research was supported by Basic Science Research Program through the National Research Foundation of Korea funded by the Ministry of Education (2013-1074).

\section{References}

1. Fernández-López, J., Sevilla, L., Sayas-Barberá, E., Navarro, C., Marin, F., and Pérez-Alvarez, J. A. (2003) Evaluation of the antioxidant potential of hyssop (Hyssopus officinalis L.) and rosemary (Rosmarinus officinalis L.) extracts in cooked pork meat. J. Food Sci. 68, 660-664.

2. Jeon, Y. J., Kamil, J. Y., and Shahidi, F. (2002) Chitosan as an edible invisible film for quality preservation of herring and Atlantic cod. J. Agr. Food Chem. 50, 5167-5178.

3. Khwaldia, K., Arab-Tehrany, E., and Desobry, S. (2010) Biopolymer coatings on paper packaging materials. Compr. Rev. Food Sci. Food Safety. 9, 82-91.

4. Kim, T. J., Silva, J. L., Kim, M. K., and Jung, Y. S. (2010) Enhanced antioxidant capacity and antimicrobial activity of tannic acid by thermal processing. Food Chem. 118, 740746.
5. Ladikos, D. and Lougovois, V. (1990) Lipid oxidation in muscle foods: A review. Food Chem. 35, 295-314.

6. Lee, J., Lee, J., and Song, K. B. (2015a) Development of a chicken feet protein film containing essential oils. Food Hydrocolloid. 46, 208-215.

7. Lee, J., Won, M., and Song, K. B. (2015b) Physical properties and antimicrobial activities of porcine meat and bone meal protein films containing coriander oil. LWT-Food Sci. Technol. 63, 700-705.

8. Nowzari, F., Shábanpour, B., and Ojagh, S. M. (2013) Comparison of chitosan-gelatin composite and bilayer coating and film effect on the quality of refrigerated rainbow trout. Food Chem. 141, 1667-1672.

9. Ojagh, S. M., Rezaei, M., Razavi, S. H., and Hosseini, S. M. H. (2010) Effect of chitosan coatings enriched with cinnamon oil on the quality of refrigerated rainbow trout. Food Chem. 120, 193-198.

10. Qin, Y. Y., Yang, J. Y., Lu, H. B., Wang, S. S., Yang, J., Yang, X. C., Chai, M., Li, L., and Cao, J. X. (2013) Effect of chitosan film incorporated with tea polyphenol on quality and shelf life of pork meat patties. Int. J. Biol. Macromol. 61, 312-316.

11. Song, N. B., Jo, W. S., Song, H. Y., Chung, K. S., Won, M., and Song, K. B. (2013) Effects of plasticizers and nano-clay content on the physical properties of chicken feather protein composite films. Food Hydrocolloid. 31, 340-345.

12. Vyncke, W. (1970) Direct determination of the thiobarbituric acid value in trichloroacetic acid extract of the fish as a measure of oxidative rancidity. Eur. J. Lipid Sci. Technol. 72, 10841087.

13. Zivanovic, S., Chi, S., and Draughon, A. F. (2005) Antimicrobial activity of chitosan films enriched with essential oils. $J$. Food Sci. 70, M45-51. 